Poster Section

\title{
Biological effects of high-diluted substances and periodic table of elements
}

\author{
Cloe Taddei-Ferretti1,2 \\ ${ }^{1}$ Istituto di Cibernetica "E. Caianiello", CNR, Pozzuoli, Italy \\ ${ }^{2}$ Scuola Italiana di Medicina Omeopatica Hahnemanniana, Rome, Italy
}

\begin{abstract}
Background and Aims. There are several experimental evidences for the effects of high-diluted substances (see e.g. C. Taddei-Ferretti, A. Cotugno 1997, on effects of high-diluted drugs on the prevention and control of mice teratogenicity induced by purine derivatives; N.C. Sukul, C. Taddei-Ferretti, S.P. Sinha Babu, A. De, B. Nandi, A. Sukul, R. Dutta-Nag 2000, on high-diluted Nux vomica countering alcohol-induced loss of righting reflex in toads). Also the physical characterization and mechanism of action of high-diluted drugs have been studied (see e.g. N.C. Sukul, A. Sukul, High dilution effects: Physical and biochemical basis 2004). However, further experimental researches are needed to clarify how physical characteristics of a drug are linked to its global biological effects. Considerations on some high-diluted mineral remedies will be developer here.
\end{abstract}

Methods. In Organon, sect. 119, S. Hahnemann writes: «As certainly each species of plants is different from every other one with regard to external appearance, way of life and growth, taste and smell, and as certainly each mineral, each salt is different from the others with regard to external, internal, physical and chemical qualities [...], so certainly all these vegetal and mineral substances have pathogenetic - and thus also curative - effects different among themselves [...]».

This statement may be taken as basis for considering the characteristics of some elements, as ordered in the periodic table, in relation to those of some high-diluted mineral remedies.

Conclusions. The elements were previously ordered in the periodic table according to the atomic weight chemically determined, and later more precisely according to the atomic number (number of protons). Then also the electronic configuration was taken into account: properties depending on atomic mass and deep electrons are not periodical, while chemical and several physical properties are linked to external electrons which have periodical configuration.

In particular, let us consider the group of elements $\mathrm{C}, \mathrm{P}, \mathrm{S}, \mathrm{Cl}$ and the group of elements $\mathrm{Ca}, \mathrm{Mg}, \mathrm{K}, \mathrm{Na}$. One may conclude that the four elements of the first group (respectively receiver-or-donor of 4 electrons, receiver of 3 , of 2 , of 1 electron), which, according to H. Bernard, are linked to the fixed human constitutions, are close among themselves in the periodic table, while they are very distant from the four elements of the second group (respectively donor of 2 , of 2 , of 1 , of 1 electron), which are close among themselves and are linked to the changing constitutional stages.

Key words: biological effects, high-diluted substances, human constitutions, periodic table, physical characteristics 


\section{(cc)) EY-NC-ND Licensed to GIRI}

Support: the author declares that this study received no funding

Conflict of interest: the author declares there is no conflict of interest

Received: 01 June 2012; Revised: 10 August 2012; Published: 30 September 2012.

Correspondence author: Cloe Taddei-Ferretti, cloetadfer@libero.it

How to cite this article: Taddei-Ferretti C. Biological effects of high-diluted substances and periodic table of elements. Int J High Dilution Res [online]. 2012 [cited YYYY Month dd]; 11(40):192-193. Proceedings of the XXVI GIRI Symposium;
2012
Sep
20-22;
Florence
(Italy).
GIRI;
2012 ;
Available
from:

http://www.feg.unesp.br/ ojs/index.php/ijhdr/article/view/613/603 